$\mathbb{T}$ periodica polytechnica

Mechanical Engineering

$54 / 2(2010) 77 \sqrt{82}$

doi: 10.3311/pp.me.2010-2.03

web: http://www.pp.bme.hu/me

(c) Periodica Polytechnica 2010

RESEARCH ARTICLE

\section{Examination method of uncoated coronary stents}

\author{
Péter Szabadíts / Tibor Balázs / Eszter Bognár / János Dobránszky
}

Received 2010-11-31

\begin{abstract}
In this study the authors show a complex examination method which allow to determine the basic features of stents on one stent as possible.These tests have three big parts as nondestructive tests transforming tests and destructive tests. The non-destructive contains optical microscope, metallographic microscope and scanning electron microscope (SEM) investigations; while the mechanical part contains tests by tensile machine and hardness measurement on the sample. Based on these procedures the recoil the crossing profile the MSA the foreshortening were measured or calculated and the flexibility the trackability the retention and the hardness weremeasured and determined.We also defined the place of the measurement of the $X$ Ray visibility (radiopacity) and the radial stiffness in the row of tests.In this study we used two commercially available coronary stents for verify the test methods, one of the stents contain a Ta layer for a better X-Ray visibility.

Our aim was to define and find the position, depth and the importance of this special layer.This article focuses on the features of stent design that make a specific stent more or less suitable for a particular type of lesion or anatomy.
\end{abstract}

\section{Keywords}

coronary stent $\cdot$ examination method $\cdot$ expansion properties . metallic surface area $\cdot$ stent retention

\section{Péter Szabadíts \\ Tibor Balázs \\ Eszter Bognár}

Department of Materials Science and Engineering, BME, H-1111, Budapest,Bertalan L.street.7, Hungary

\section{János Dobránszky}

Research Group for Metals Technology of HAS and BME, H1111,Budapest,Bertalan L.street.7, Hungary

\section{Introduction}

It was in 1994 that the U. S. Food and Drug Administration (FDA)approved the balloon-expandable coronary stent (Fig. 1) for the prevention of restenosis [1]. It brings on many changes thedevelopment of the stents has paralleled the evolution of endovascular intervention as a new specialty [2].

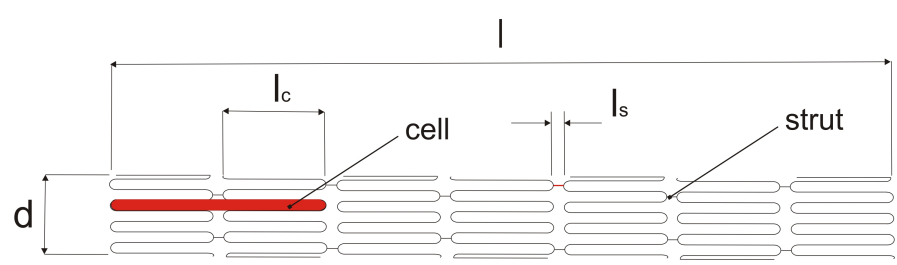

Fig. 1. Measures of the stent

Year by year appeared new desirable features and abilities that the stents had to reach [3.4]. The first generations of stents were made of wire and the appearance was helical spiral or woven wire. The second generations of stents are produced by laser cutting from stainless steel tubes [5, 6]. The vast majority of stents are laser cut from 316L stainless steel [7]. Once the tube-like mesh stent is positioned correctly within the coronary artery, a balloon catheter is used to expand the stent which subsequently maintains vessel patency via its ability to sustain stress in the radial direction [3, 8]. Many of theengineering considerations in stent design were adopted to improve the global acceptability of the device, rather than making a stent design for a specific type of coronary lesion [9, 10].In clinical practice, the operator must decide which stent is most appropriate for the patient. Stents can be classified according to their mechanism of expansion (selfexpanding or balloon expandable), their composition (stainless steel, cobalt-based alloy, tantalum, nitinol, inert coating, active coating, biodegradable, etc.), and their design (mesh structure, coil, slotted tube, ring, multi-design, custom design, etc.). The stents have many features which are measurable or calculable by the measured parameters Fig. 1. The aim of this work was to determine as many properties of one stent as it possible before and after expansion. 


\section{Experimental}

Materials commercially available coronary stents were used. Strategy The order of investigations has to be plannedto ensure the highest possible number of tests to be performed with a single stent of high value [11,12]. In sequence of testing protocol, the non-destructive methods (stereo- or metallographic microscopy and imaging) were applied at first these were followed the methods which need the stent transformation (inflation the stent) and final the destruction examinations Fig. 2

The steps of the investigations were the followings:

1 measuring the dimensions (length and diameter) of stents by microscope

2 measuring the crossing profile

3 measuring X-Ray visibility of mounted stents

4 measuring flexibility of mounted stents by tensile machine

5 measuring trackability of mounted stents by tensile machine

6 measuring the pull down force of stent by tensile machine

7 inflating one stent

8 measuring the dimensions (length and diameter) of inflatedstents

9 calculating the foreshortening of inflated stent

10 calculating the recoil of inflated stent

11 measuring the MSA of inflated stent

12 measuring X-Ray visibility of inflated stents

13 measuring flexibility of inflated stents by tensile machine

14 measuring the crush resistance of inflated stents by tensile machine

15 preparing the stents for electron microscopy and hardness test

16 measuring the hardness of row material

17 EDS analysis to determine the elements of the raw material.

\section{Methods}

For the examination of surface properties, dimension, stent design and MSA stereo microscope (Nikon SMZ2T), metallographic microscope (Olympus PMG-3) and scanning electron microscope [SEM] (Philips XL 30) were used. Stent flexibility, trackability, retention and crush resistance were determined by tensile test equipment (Zwick Z005). Some features of stent are defined from the measured parameter as crossing profiles, recoil, foreshortening [13]. Dimensions to identify clearly the dimensions of stentswe used stereo microscope. The measurement does not have any effect of other properties of stent. The measurement can be carried out in crimped and dilated stent [14]. The length of stent which are measured when mounted

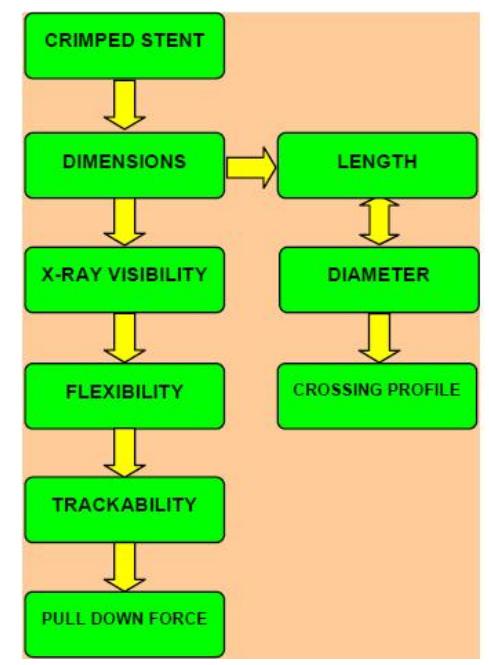

Fig. 2.

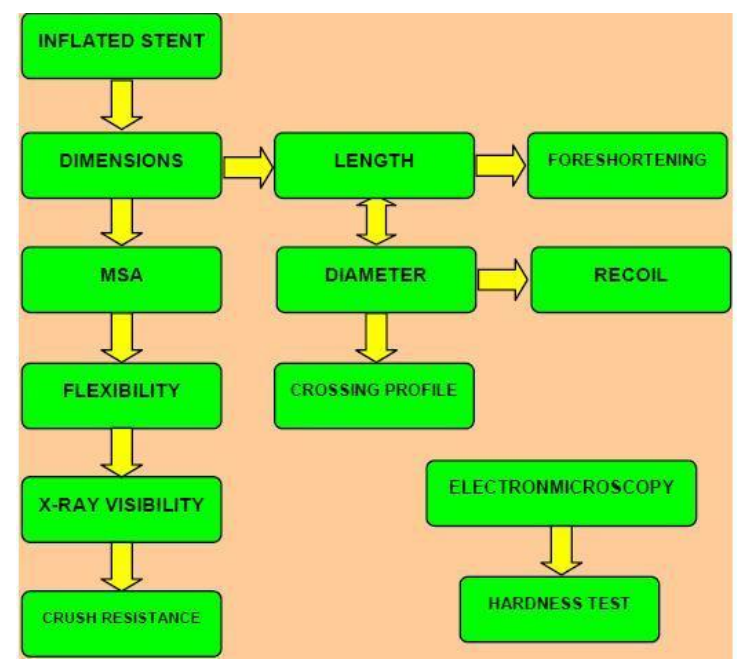

Fig. 3.

thestent on the balloon. In case of implant designs where the length changes as a function of the expanded diameter the corresponding lengths and diameter shall be measured. The diameter is determined by the inflating pressure.Crossing profile is ellipsoid the two axis of this ellipsoid are the stents highest diameter and the $90^{\circ}$ degree rotated diameter which are measured when mounted the stent on the balloon [11]. Flexibility to identify clearly the flexibility of stents we used tensile test equipment. The measurement does not have any effect of other properties of stent.

The measurement can be carried out in crimped and dilated stent. The flexibility is the ability of the stent and delivery system's to have sufficient flexibility to negotiate the vascular anatomy without compromising the function of the implant. High degree of longitudinal stent flexibility is required for easy delivery of the stent through the vasculature to the stenotic lesion [15, 16]. Trackability to identify clearly the trackability of stents we used tensile test equipment. The measurement does not have any effect of other properties of stent. The measurement can be carried out only in dilated stent. The trackability is the ability of the stent and delivery system's to advance over 
the guide-wire along the path of vesselin a simulated anatomy. Quantitative assessment is not required by the standard [17].

Dislodgment force or pull down force to identify clearly the dislodgment force of stents we used tensiletest equipment.It is a destructive test, the stent is usable within limits for further tests. Dislodgment force is a force which needed to the mounted stent to slip down from the balloon [18].

Recoil to identify clearly the recoil of stents we usedmeasuring microscope. The measurement does not have any effect of other properties of stent. The measurement can be carried out in dilated stent [13]. The recoil amount by which the diameter of an implant changes from its initial diameter when still on its fully inflated delivery system to its relaxed final diameter after deflating the system, expressed as percentage of the diameter measures when still on the fully inflated delivery system. Implant recoil $\%=\left[\left(\right.\right.$ Diameter $_{\text {inflated }}-$ Diameter $\left._{\text {final }}\right) /$ Diameter $\left._{\text {inflated }}\right] \times 100$.

Foreshortening to identify clearly the foreshortening of stents we used measuring microscope. The measurement does not have any effect of other properties of stent. The measurement can be carried out in dilated stent [13]. The foreshortening mechanism describes the longitudinalcontraction of the stent under dilation. Implant foreshortening $\%=\left[\left(\right.\right.$ Length $_{\text {crimped }}-$ Length $\left._{\text {final }}\right) /$ Length $\left._{\text {crimped }}\right] \times 100$.

MSA to identify clearly the MSA of stents we used measuring microscope. The measurement does not have any effect of other properties of stent. The measurement can be carried out in dilated stent [11, 12]. The MSA is the percentage of the surface area of the cylinder formed by the implant frame, which is covered by implant material, (1-implant free surface area). $\mathrm{X}$-Ray visibility or radiopacity the X-Ray visibility is the implant shall be visible under validated imaging techniques used clinically [13-19]. Crush resistanceto identify clearly the crush resistance force of stents we used tensile test equipment. It is a destructive test, the stent is usable within limits for further tests. The crush resistance is the change in implant diameter shall be measured as a function of circumferential applied pressure or radial force until permanent deformation. This is sometimes also called "rigidity" or "radial rigidity" or the radial stiffness describes the resistance of a fully expanded stent against compression, or, in other words, the resistance to being pressedtogether. A stent may have a high or low radial stiffness. Radial stiffness of the stent is the resistance to the displayedexternal compression [20,21].

\subsection{Hardness}

The micro-hardness test proved to be a very capable technique for examining the mechanical properties of stents. A ground finish is made and the stents are combined with the binary Duracryl resin. The resin, which is made relatively liquid, surrounded the samples and filled out the smaller parts.It is the intersections of these stents that are needed. Therefore, the surface that was in contact with the glass plate was rubbed down with coarse grade silicon carbide sandpaper (P80). During this process, the level of the sample's polished surface was also set. The last step involved the ground finish being treated with absolute ethanol to remove the water contamination from the surface of the ground finish during the previous procedures. The measurements were carried out using a micro-hardness tester. Material composition microanalysis (EDS) were executed on the surface of the stent as well that shows the precise content of the coating and the materials for elements, which have $\mathrm{Z}>8$ atomic number. Some stent composite of stainless steel and tantalum which give an excellent radiopacity ultra thin struts low crossing profile high level of flexibility an optimized scaffolding and unmached conformability these features help to implant the stent into thesmall vessels.

\section{Results and discussion}

\subsection{Dimensions}

Length and diameterthe length and the diameter of the stent are measurable in crimped state and in dilated state as well.The length of stent was $15 \mathrm{~mm} \pm 0.22 \mathrm{~mm}$. in crimped state and the length was $14.56 \mathrm{~mm} \pm 0.35 \mathrm{~mm}$ in dilated state Fig. 4 .

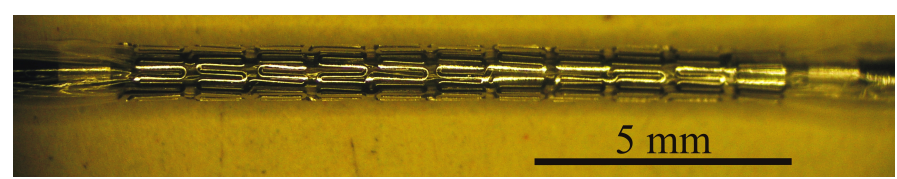

Fig. 4.

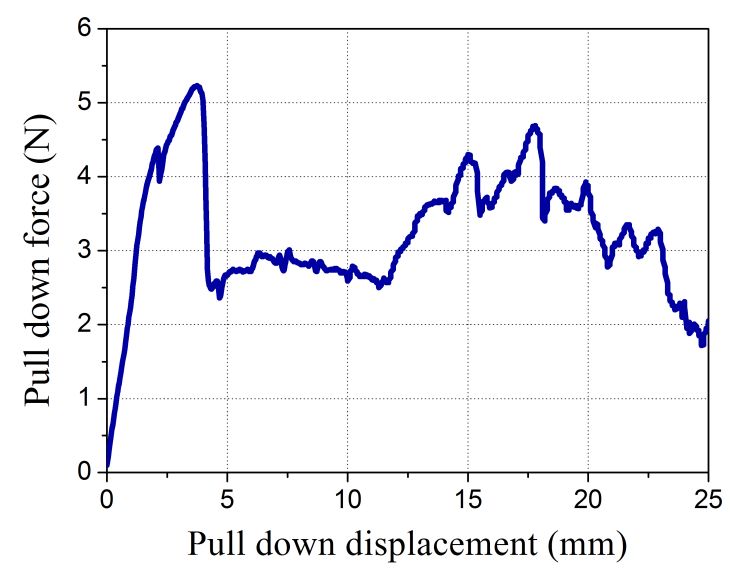

Fig. 5.

The maximal outside diameter of stent was $1.1 \mathrm{~mm}$ in crimped state at the 3 th distal ring and the minimal outside diameter was $0.95 \mathrm{~mm}$ in crimped state at the 2 th proximal ring. The maximal outside diameter of stent was $2.2 \mathrm{~mm}$ in dilated state at the 2 th distal ring and the minimal outside diameter was $2.15 \mathrm{~mm}$ in dilated state at the 5th proximal ring Fig.5 Crossing profile the crossing profile is ellipsoid the two axis of this ellipsoid are the stent maximal diameter and the $90^{\circ}$ degree rotated diameter.The maximal diameter was $1.1 \mathrm{~mm}$ and the $90^{\circ}$ degree rotated diameter was $1.0 \mathrm{~mm}$. Recoil the inflating pressure was 


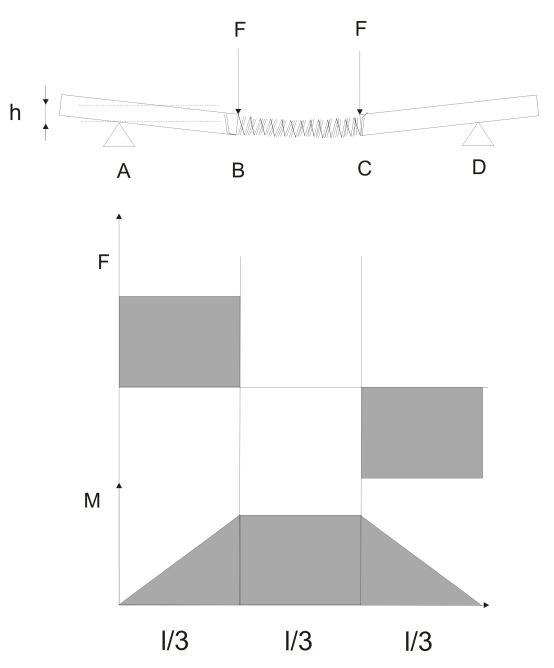

Fig. 6. four point bending test

8 bar and by the datathe diameter of stent had to be $2.25 \mathrm{~mm}$. The measured, final diameter was only $2.2 \mathrm{~mm}$ and the recoil was $2.2 \%$. Foreshortening the length of stent in crimped state was $15 \mathrm{~mm}$ and the dilated was only $14.56 \mathrm{~mm}$, the foreshortening was $2.29 \%$. Flexibility the flexibility of expanded stentswas tested with two different methods. The first one was the onepoint bending test the second was the four point bending test (Fig. 6), thereby allowing for application of a constant moment to the specimen.

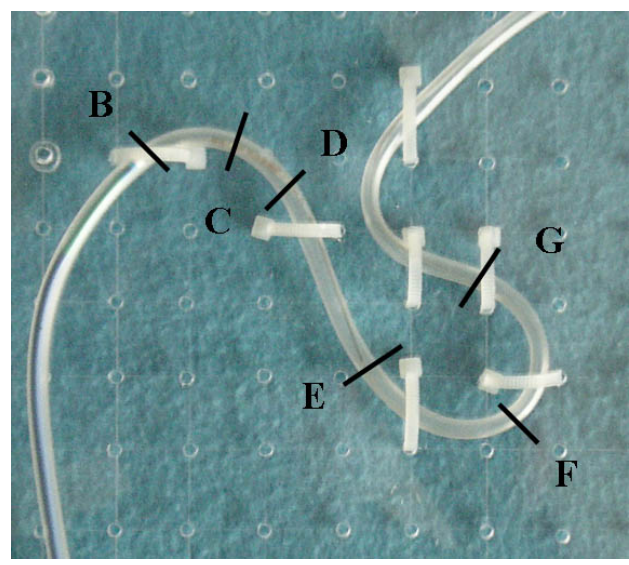

Fig. 7.

$$
\begin{aligned}
\tan \varphi & =\frac{\mathrm{h}}{\mathrm{L} / 3} \\
\mathrm{E} \cdot \mathrm{I} & =\frac{\mathrm{M}_{0} \cdot(\mathrm{L} / 3)^{2}}{8 \cdot \mathrm{f}}\left[\mathrm{Nmm}^{2}\right] \\
\alpha_{\mathrm{BD}} & =\pi / 2, \mathrm{R}_{\mathrm{BD}}=30 \mathrm{~mm}, \alpha_{\mathrm{EG}}=\pi, \mathrm{R}_{\mathrm{EG}}=15 \mathrm{~mm} .
\end{aligned}
$$

The distance between the support points $\mathrm{A}$ and $\mathrm{D}$ is $(\mathrm{L})$ where $(\mathrm{L} / 3)$ is the length of the tested stent. The displacement of thecontact points of the punch $\mathrm{B}$ and $\mathrm{C}$ are defined as $(\mathrm{h})$ then the rods make an angle $(\varphi)$ represented by Eq. (2). The $\mathrm{h}_{\max }$ was $5 \mathrm{~mm}$ to avoid the stentdamage. The constant moment $\left(\mathrm{M}_{0}=\mathrm{F} \cdot \mathrm{L} / 3\right)$ is applied between points $\mathrm{B}$ and $\mathrm{C}$. In this case the deflection of the stent is equal to that of the supported beam, which makes an angle of $(\varphi)$ at the bothends of the beam under constant moment. Therefore the flexibility (E.I) is represented by Eq. (2). Fig. 8 shows the calculated E.I curves by Eq. (3) in function of the displacement in case of four-point bending test. The curve focuses a discrete value. This value is the flexibility of stent.

Trackability system's trackability tests were performedusing an in vitro coronary vessel model Fig. 8, which parameters were: $\mathrm{AB}=20 \mathrm{~mm}, \mathrm{BC}=25 \mathrm{~mm}, \mathrm{CD}=20 \mathrm{~mm}, \mathrm{DE}=55 \mathrm{~mm}$, $\mathrm{EF}=35 \mathrm{~mm}, \mathrm{FG}=35 \mathrm{~mm}$. The maximum attainment distance was $\mathrm{BG}=165 \mathrm{~mm}$. The stent delivery systems were able to go over position $\mathrm{G}$. At the start position the end of the guiding catheter and the tip of the delivery system were at the point B. Each stent and delivery systems were measured three times.

The examined stent and delivery system passed the vessel model without damage and reproducible results in the force measurements were achieved. The force distance curves of the trackability tests are shown in Fig. 9

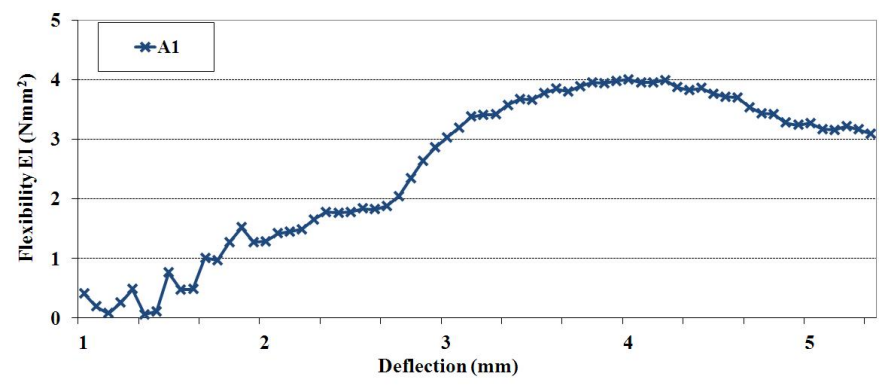

Fig. 8.

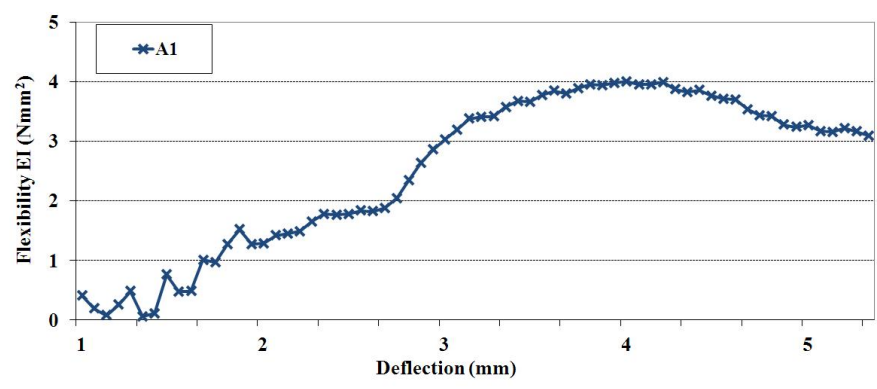

Fig. 9.

Dislodgment force or pull down force the stent dislodgment force is usually defined as the force which is required to move the crimped stent on the evacuated balloon. Basically the force what is needed to the stent moved relative to the balloon is taken as the stent dislodgment force, but in our experiments we use the maximum force as stent retention. The reason of it, because if the stent first moves on the balloon it is still on there and a higher pull forces necessary for the stent moved over the distal balloon shoulder. The stent retention or pull down force is the force which is required to pull down the crimped stent from the balloon. To test stent retention, the balloon-mounted stents were fixed with an adhesive layer and placed into the upper clamp of the tensile equipment. In the lower clamp of the tensile equip- 
Tab. 1. EDS results of the applied material (12 kV beam voltage)

\begin{tabular}{lllllllll}
\hline Element & $\mathrm{C}$ & $\mathrm{Si}$ & $\mathrm{Mo}$ & $\mathrm{Cr}$ & $\mathrm{Mn}$ & $\mathrm{Fe}$ & $\mathrm{Ni}$ & Total \\
\hline Weight\% & 4,56 & 0,52 & 2,92 & 17,52 & 2,26 & 58,09 & 14,12 & 100,00 \\
Atomic\% & 18,20 & 0,89 & 1,46 & 16,14 & 1,97 & 49,82 & 11,52 & 100,00 \\
\hline
\end{tabular}

ment the catheter was fixed. During the movement of the upper and lower jaws of the tensile equipment, the stent was pulled down from the balloon. The maximum force required was $F_{\text {RET }}$ $=5.4 \mathrm{~N}$. This force iscomplied with the specifications Fig. 10 shows the pull down force in function of the pull down displacement.

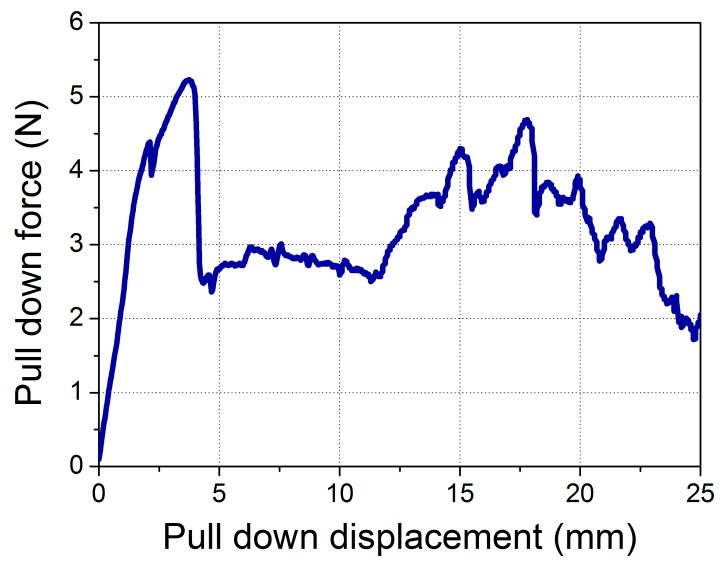

Fig. 10.

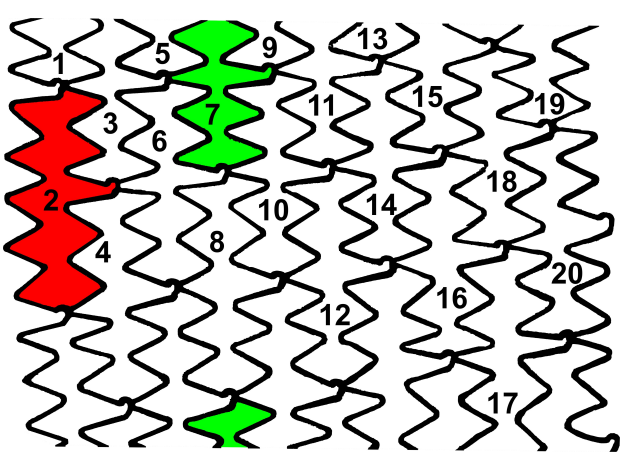

Fig. 11. MSA the layout of the expanded stent

MSA the layout of the expanded stent was demonstrated using a self development stent rotating equipment. Photos were taken by stereo microscope from each part of the expanded stent during the rotation of the stent. The pictures were joined to each other to create the layout. This edited photo can be seen in Fig. 11. The total MSA was $19.8 \%$. The area of largest cell was \#2 4.1\% the area of smallest cell was \#7 3.0\% the average area of cell surface was $3.5 \%$. Hardness the measurements were carried out in the Ta and the 316 layers and their border as well (Fig. 12).

The results are shown below. The Vickers hardness of the Ta layer was 160,0 HV 10 with 5,7 HV10 deviation; the 316L stainless steel has the hardness in thesame order 162,2 HV 10 with $11,6 \mathrm{HV} 10$ deviation. The numbers of the measurements on the

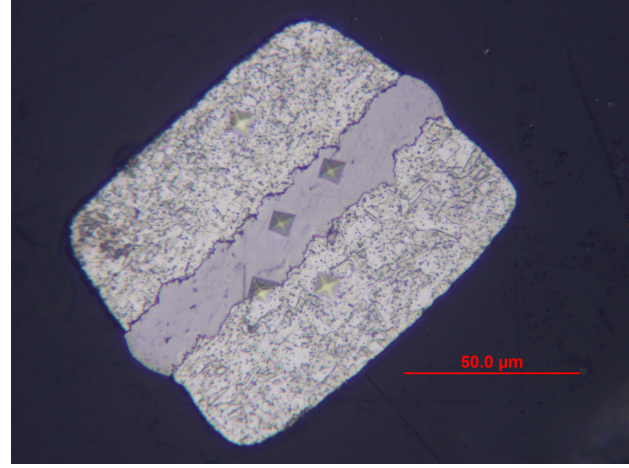

Fig. 12.

samples were 5 from each types of material.Material composition as a result of the electron microscopic and the energy dispersive analysis, it can be concluded that the base material of the stent is 316L type stainless steel with a Ta layer Tab. 1. This Ta layer is separated in the photographs as well.

\section{Conclusions}

In summary we are confronted with more than 50 different stent properties. Why? This development has mainly been driven by patent and marketing issues rather than actual scientific considerations.Some properties of the stent are not clearly formulated in the standard. The clinical trials which in fact they can decide which stent isbetter but these tests are very expensive. Some properties of stent are important during the implantation of stent as crossing profile, X-Ray visibility, flexibility, trackability and pull down force. The other examined properties of stent are important for the long term effect of stent after the implantation as foreshortening, recoil, MSA, crush resistance, hardness of row material and material composition. It is essential that the stents can also examine the main characteristics of comparative studies when one of the stents compared to the others. Such comparative studies it is essential that a structured method of analysis can be evaluated and to determine as many properties of one stent as it possible before and after expansion. We can defined 15 properties of stents and we used only two stents to tests. This will certainly help us to discriminate actual achievements from 'me too' products and will enable us to get closer to the 'ideal stent'. Metallographic microscope with its high magnification is suitable to examine smaller geometric and surface alterations and defects. This method is appropriate to determine the surface quality, to characterize and compare the stent surface before and after expansion or other stresses.In testing of stent coating morphology, defects and damages electron microscope provides the best results. The stent length and diam- 
eter compared with data from the specified factory was slightly different. The difference may also be explained, for those parameters that stents are not always easy to measure, because stent has sometimes just a virtual boundary.

\section{Acknowledgement}

Authors wish to thank Istvánné Hrotkó, Mihály Portkó, Márk Hatala and BME Department of Polymer Engineering. This work is connected to the scientific program of the "Development of quality-oriented and harmonized $\mathrm{R}+\mathrm{D}+\mathrm{I}$ strategy and functional model at BME" project. This project is supported by the New Széchenyi Plan (Project ID: TÁMOP-4.2.1/B-09/1/KMR2010-0002).

\section{References}

1 Julio L, Palmaz J C, Intravascular Stents in the Last and the Next 10 Years, Journal of Endovascular Therapy, 11(2), (2004), 200-206.

2 Schmidt W, Behrens P, Schmitz K P, New Aspects of in vitroTesting of Arterial Stents based on the new European Standard EN14299, Biomed. Techn,Institute for Biomedical Engineering, University of Rostock, Germany, 50, (2005), 861-862.

3 Lau K, Mak K, Hung J, Sigwart U, Clinical impact of stent construction and design in percutaneous coronary intervention, Am Heart J, 147, (2004), 764-73.

4 2010.07.14, available at /WwW.abbottvascular.com/av_dotcom/ url/content/en_US/10.10.365.10:10/general_content/Abtdiv_ General_Content_0000159.htm\#1

5 Dyet J F, Watts W G, Ettles D F, Anthony A, Nicholson, Mechanical properties of metallic stents: How do these properties influence the choice of stent for specific lesions, Dardiovasc Intervent Radiol, 23, (2000), 47-54.

6 Mani G, Feldman M D, Patel D, Coronary stents: Amaterials perspective, Biomaterials, 28, (2007), 1689-1710.

7 Hanawa T, Materials for metallic stents, J Artif Organs, 12, (2009), 73-79.

8 Rieu R, Barragan P, Radial Force of Coronary Stents: A Comparative Analysis, Catheterization and Cardiovascular Interventions, 46, (1999), 380-391.

9 Jedwab M, Clerc C, A study of the geometrical and mechanical properties of self-expanding metallic stents - theory and experiment, J. Appl. Biomater, 4, (1993), 77-85.

10 Hara H, Nakamura M, Palmaz J C, Role of stent design and coatings on restenosis and thrombosis, Advanced Drug Delivery Reviews, 58, (2006), 377-386

11 Ring G, Koszorúérsztentek in vitro és in vivo vizsgálata és vizsgálati módszereinek fejlesztése, (2005). Diplomamunka, BME ATT.

12 Pataki B Z, Bognár E, Ring G, Dobránszky J, Ginsztler J, Koszorú érsztentek vizsgálata, GÉP, LVII évf, (2006/11), 3-7.

13 Ring G, Bognár E, Pataki B, Dobránszky J, Different Properties of Coronary Stents, Anyagok Világa -Materials World, 7, (2007/2),/www.kfki .hu/ anyag/Ring.pdf

14 Schmidt W, Behrens P, In vitro measurement of quality parameters of stent-catheter systems, Biomedical Technology, 50, (2005), 1505-1506.

15 Mori K, Saito T, Effects of stent structure on stent flexibility measurements, Annals of Biomedical Engineering, 33, (2005), 733-742.

16 Petrini P, Migliavacc F, Auricchio F, Dubini G, Numerical investigation of the intravascular coronary stent flexibility, Journal of Biomechanics, 37, (2004), 495-501.

17 Schmidt W, Grabow N, Behrens P, Schmitz K P, Measurements of mechanical properties of coronary stents according to the Eurpean standard prEN 12006-3, Progress in Biomedical Research, 4(1), (1999), 47-53.
18 Kent D, Knott B, Stigall J, Stent retention mold and method, WO, 2008/005467 A2, (2008).

19 Steegmüller R, Strobel M, Flaxmeier E, Schuessler A, Micro-Welding for Improved Radiopacity of Nitinol-Stents.SMST-2004, Proceedings of the International Conference on Shape Memory and Superelastic Technologies, (2006), 591-595.

20 Nuutinen J P, Clerc C, Törmala P, Theoretical and experimental evaluation of the radial force of self-expanding braided bioabsorbable stents, $\mathrm{J}$ of Biomaterials Science,Polymer Edition, 14, (2003.07), 677-687.

21 Vorwerk D, Redha F, Neuerburg J, Clerc C, Günther R W, Neointima formation following arterial placement of self-expanding stents of different radial force: Experimental results, CardioVascular and Interventional Radiology, 17, (1994), 27-32. 